\title{
TECNOLOGIAS DE APLICAÇÃO DE PRODUTOS FITOSSANITÁRIOS NO CONTROLE DE PERCEVEJOS PRAGAS NA CULTURA DA SOJA
}

\section{E.P.Prado, C.G. Raetano, R.S. Christovam, H.O. Aguiar-Júnior, M.H.F.A. Dal Pogetto}

Universidade Estadual Paulista, Faculdade de Ciências Agronômicas, Departamento de Produção VegetalDefesa Fitossanitária, CP 237, CEP 18610-237, Botucatu, SP, Brasil. E-mail: epprado@hotmail.com

\section{RESUMO}

\begin{abstract}
Os percevejos fitófagos são importantes insetos-pragas na cultura da soja, causando danos desde a formação das vagens até o final do desenvolvimento dos grãos. O trabalho objetivou avaliar o controle desses insetos-pragas (complexo de percevejos) após o tratamento com inseticidas sob duas velocidades da assistência de ar junto à barra de pulverização combinadas a duas pontas de pulverização. Dois experimentos foram conduzidos na Faculdade de Ciências Agronômicas/UNESP - Campus de Botucatu, safra 2006/2007 na cultura da soja, var. Conquista, no delineamento experimental em blocos ao acaso, com esquema fatorial $2 \times 2+1$ (dois níveis de ar, 0 e 100\%; duas pontas de pulverização, JA-2 e AXI 11002, mais testemunha). No estádio de desenvolvimento R6 foi realizada uma pulverização com os inseticidas tiametoxam associado com lambda-cialotrina (experimento 1) na dosagem de 25,38 + 19,08 g i.a. ha-1 e endosulfan (experimento 2) na dosagem de 437,5 g.i.a. ha-1 . A aplicação foi feita com um pulverizador Advanced Vortex 2000 conferindo um volume de calda de $200 \mathrm{~L} \mathrm{ha}^{-1}$. As avaliações antes (prévia) e com 1, 3, 6, 10 e 14 dias após a aplicação foram realizadas pelo método do pano-de-batidas. O número médio de percevejos foi significativamente menor nas parcelas tratadas em relação àquelas não tratadas. De modo geral, não houve diferença estatística entre as tecnologias de aplicação em ambos os experimentos.
\end{abstract}

PALAVRAS-CHAVE: Controle químico, pentatomidae, pragas da soja, técnicas de aplicação.

\section{ABSTRACT}

EFFECT OF PESTICIDE APPLICATION TECHNOLOGIES IN THE CONTROL OF STINK BUGS IN THE SOYBEAN CROP. Stink bugs are an important pest in the soybean crop. The aim of this research was to evaluate the control of this pest with pesticides applied at two air speeds using an air assisted sleeve boom sprayer arranged with two nozzles. Two experiments were carried out at FCA/UNESP Botucatu, SP (Brazil), using soybean plants of the Conquista variety (season 2006/2007). The experimental design was randomized blocks with 5 treatments and 4 repetitions in a $2 \times 2+1$ factorial scheme (two levels of air speed, 0 and 100\%, two nozzles: flat fan nozzle AXI 11002 and hollow cone nozzle JA-2, plus nontreated plots). The insecticide tiametoxam associated with lambdacialotrina (experiment 1 ) at $25.38+19.08$ g i.a. ha $^{-1}$ and endosulfan (experiment 2 ) at 437.5 g.i.a. per hectare were applied in the growth stage V6 with support of the spray Advanced Vortex 2000 using a volume rates of $200 \mathrm{~L} \mathrm{ha}^{-1}$ for both treatments and experiments. The evaluations before (0) and 1 , $3,6,10$ and 14 days after applications were made by the method of hits on the cloth. The average numbers of stink bugs were significantly lower in treated plots in relation to nontreated plots. In general, there was no statistical difference between the application technologies in both experiments.

KEY WORDS: Chemical control, pentatomidae pests, application technique.

\section{INTRODUÇÃO}

A soja [Glycine max (L.) Merrill.] é uma cultura atacada por diversos insetos-pragas. Dentre os que causam maiores danos, destacam-se as espécies de percevejos fitófagos, causando sérios prejuizos aos sojicultores. Os percevejos estão presentes em todas as regiões produtoras do país e seus danos refletem diretamente na produção e qualidade da semente (RAMiro et al., 2005).

O ataque dos percevejos durante a fase de formação de grãos ocasiona o aborto de grãos ou de vagens. No enchimento de grãos, pode causar enrugamento, deformações, redução da produtividadee da qualidade das sementes, além disso, pode causar retenção foliar ou presença de caules verdes dificultando a 
colheita mecânica (GAZZONI, 1998). Segundo esse autor, os percevejos colonizam as plantas de soja em diversos estádios de desenvolvimento, porém a capacidade de causar danos está limitado a sua alimentação nas vagens e sementes, durante o subperíodo de formação até o amadurecimento das vagens.

Embora existam vários trabalhos comprovando a eficiência de agentes de controle biológico com parasitoides de ovos de percevejos (CORRÊA-FERREIRA, 1993; Godoy; Ávila, 2000; Godor et al., 2005), o controle químico ainda é o método mais utilizado e considerado mais eficiente para a praga em questão.

Um dos fatores importantes para o sucesso das aplicações éo estudo das relações entre o tipo de alvo a seratingido, a forma deaçãodo produto fitossanitário e a técnica adotada para a aplicação (ANTUNIASSI, 2004). BAUER et al. (2008), estudando os efeitos das pontas de pulverização AXI11002,JA-2 e da assistência de ar junto à barra na deposição da pulverização em soja (estádio de desenvolvimento R5.2), verificaram que as pontas AXI 11002 com assistência de ar apresentaram maiores depósitos de calda em comparação à ausência desse fator.

Inúmeros são os relatos de insucesso do controle químico de insetos que, em muitos casos, não estão associados à ineficiência do produto utilizado e sim à tecnologia de aplicação empregada. A escolha correta da ponta de pulverização, proporcionando gotas de tamanhos ideais e o auxílio da assistência de ar junto à barra de pulverização, pode contribuir para o aumento da penetração e deposição dos produtos fitossanitários no terço médio einferior da cultura da soja (BAUER; RAETANO, 2000; RAETANO; BAUER, 2003; RAetANo; Merlin, 2006; Bauer et al., 2008). Dessa forma, alvos biológicos como o próprio inseto e o seu lugar de alimentação (legumes) podem ser atingidos demaneira eficiente proporcionando um melhorcontrole do inseto em questão.

Normalmente são realizadas aplicações de inseticidas com ponta de jato cônico vazio, estas, porém, produzem gotas de diâmetro mediano volumétrico (DMV) reduzido causando um maior desvio da sua trajetória desejada principalmente em condições não apropriadas para pulverizações como a baixa umidade relativa do ar e ventos acima de $10 \mathrm{~km} \mathrm{~h}^{-1}$. Já as pontas de jato plano, no geral, produzem gotas de maior DMV diminuindo assim as chances de deriva, porém não são usualmente empregadas no controle de percevejos fitófagos na cultura da soja.

Dessa forma, o trabalho teve como objetivo avaliar a eficiência das pontas de pulverização hidráulicas de jato plano AXI 11002 e jato cônico vazio JA-2, na presença ou não da assistência de ar junto à barra de pulverização no controle dos percevejos-pragas da soja.

\section{MATERIALEMÉTODOS}

Dois experimentos foram realizados durante a safra agrícola 2006/2007, em área experimental da fazenda de Ensino, Pesquisa e Produção (FEPP) da FCA/UNESP - Campus de Botucatu, Gleba Cascalheira, na cultura da soja, var. Conquista. Aárea está situada a $724 \mathrm{~m}$ de altitude com as seguintes coordenadas geográficas: $22^{\circ} 48^{\prime} 59,7^{\prime \prime} \mathrm{Se} 48^{\circ} 25^{\prime} 38,2^{\prime \prime}$ $\mathrm{O}$, com vento predominante no sentido Leste para Oeste.

A semeadura da soja foi realizada no dia 18/12/ 2006 com espaçamento de 0,45 m entre linhas e densidade de 18 sementes $\mathrm{m}^{-1}$, conduzida em sistema convencional de semeadura.

\section{Experimento 1}

Nesse experimento, os cinco tratamentos foram estabelecidos no delineamento experimental emblocos ao acaso, em esquema fatorial $2 \times 2+1$ (dois tipos de pontas de pulverização; duas tecnologias de aplicação; tratamento adicional sem aplicação de inseticida), totalizando-se 5 tratamentos: 1) ponta de jato plano AXI11002 sem assistência dear;2) ponta de jato plano AXI 11002 com assistência de ar; 3) ponta de jato cônico JA-2 sem assistência de ar; 4) ponta de jato cônicoJA-2 com assistência de ar; 5) testemunha, com 4 repetições, totalizando-se 20 parcelas As parcelas tiveram dimensões de $8,0 \mathrm{~m}$ de largura por $10 \mathrm{~m}$ de comprimento, totalizando $80 \mathrm{~m}^{2}$ em cada parcela e $320 \mathrm{~m}^{2}$ por tratamento.

Um pulverizador com assistência de ar junto à barra de pulverização, modelo Advanced Vortex 2000, equipado com barra de pulverização de $18,5 \mathrm{~m}$ de comprimento e 37 bicos de pulverização, espaçados de $0,5 \mathrm{~m}$, foi utilizado nas pulverizações com o uso dessa tecnologia no modo ligado (com assistência de ar e operando na velocidade máxima do ventilador à $29 \mathrm{~km} \mathrm{~h}^{-1}$ ) e desligado (sem assistência de ar). A ponta de pulverização de jato plano AXI 11002 operou à pressão de $270 \mathrm{kPa}$ conferindo um volume decalda de $200 \mathrm{~L} \mathrm{ha}^{-1} \mathrm{e}$ a ponta de jato cônico vazio JA-2 operou à pressão de $630 \mathrm{kPa}$ conferindo o mesmo volume de calda da ponta de jato plano. Ambas as pontas de pulverização foram mantidas a $0,5 \mathrm{~m}$ de altura em relação ao ponteiro das plantas de soja com velocidade de deslocamento do conjunto trator-pulverizador de $5,0 \mathrm{~km} \mathrm{~h}^{-1}$.

Nesse experimento utilizou-se o inseticida tiametoxam associado com lambda-cialotrina (141+ $106 \mathrm{~g} \mathrm{~L}^{-1}$ do ingrediente ativo) na dosagem de 25,38 + $19,08 \mathrm{~g}$ i.a. ha ${ }^{-1}$. A pulverização foi realizada no dia $30 / 3 / 2007$, iniciando-se às $9 \mathrm{~h}$ e $25 \mathrm{~min}$, finalizando às 10 he 30 min com as seguintes condições ambientais: temperatura de $29,0 \pm 2^{\circ} \mathrm{C}$; umidade relativa do ar de 
$65 \pm 5 \%$ e velocidade do vento oscilando entre 6,5 a 9,0 $\mathrm{km} \mathrm{h}^{-1}$.

\section{Experimento 2}

No segundo experimento utilizou-se o mesmo delineamento experimental e tratamentos do experimento 1, porém utilizou-se o inseticida endosulfan (350 g L-1 do i.a.) na dosagem de 437,5 g.i.a. ha-1. A aplicação foi feita no mesmo dia iniciando às $10 \mathrm{~h} \mathrm{e} 45$ min e finalizando às $12 \mathrm{~h}$ com as seguintes condições ambientais: temperatura de $29,5 \pm 2^{\circ} \mathrm{C}$; umidade relativa do ar de $63 \pm 5 \%$ e velocidade do vento oscilando entre 4,0 a $6,5 \mathrm{~km} \mathrm{~h}^{-1}$.

As populações dos insetos foram avaliadas semanalmente, a partir do início do desenvolvimento de vagens, estádio de desenvolvimento $\mathrm{R}_{3}$ (FEHR et al., $1971)$, até o final da maturação fisiológica $\left(R_{7}\right)$, por amostragens pelo método do pano-de-batidas. Foram realizadas 6 avaliações: antes da aplicação (prévia) e com 1,3, 6, 10 e 14 dias após aplicação(DAA). Ao final das avaliações foram somados os números de percevejos contabilizados em cada avaliação.

Foram realizadas três amostras, ao acaso, por parcela (área útil de $6 \times 8 \mathrm{~m}$ ), contando-se os números deninfas grandes (a partir do terceiroínstar) eadultos do complexo de percevejos pragas que foram contabilizados em conjunto ede Euschistus heros (Fig. 1) que foi contabilizado isoladamente, totalizando 12 amostras para cada tratamento em cada avaliação. Quando foi atingido um índice médio próximo a 2 percevejos por pano-de-batida para o experimento 1 e 2,4 percevejos para o experimento 2, realizou-seuma única pulverização do respectivo inseticida no estádio reprodutivo $\mathrm{R}_{6}$ da cultura.

Durante a condução dos experimentos, a população de E. heros foi predominante e, face à maior quantidade desse inseto na área experimental, fez-se a

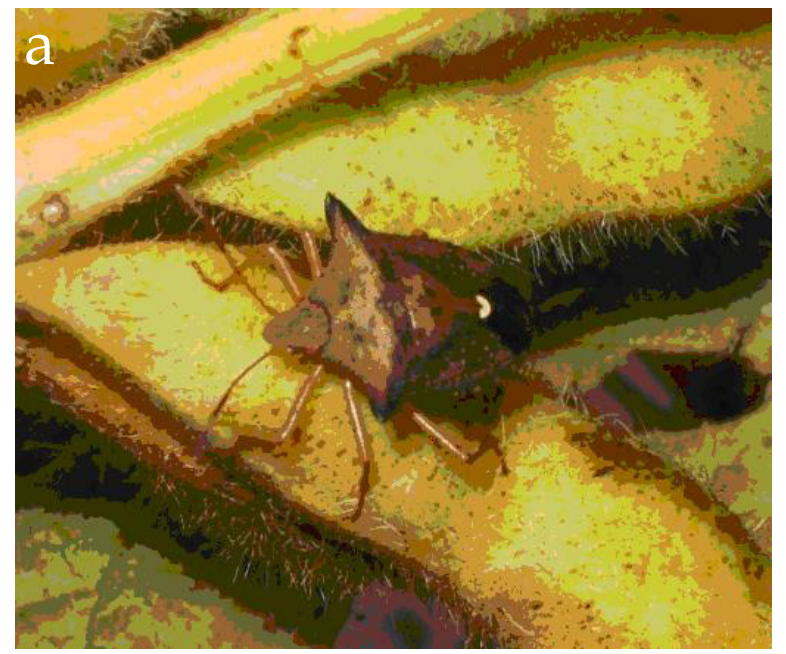

opção de separá-los dos demais percevejos, estudando o efeito das diferentes técnicas de pulverização separadamente sobre a população do percevejo $E$. heros e sobre a população do complexo de percevejos fitófagos da soja.

Os dados originais de contagens dos percevejos foram transformados em raiz quadrada de $x+0,5$ e submetidos à análise de variância feita no esquema fatorial $2 \times 2+1$ (pontas $x$ assistência de ar + testemunha) e a comparação das médias feita pelo teste de Tukey a $5 \%$ de probabilidade. As porcentagens de eficiência foram calculadas por HENDERSON; TILTON (1955). Todas as análises foram feitas com auxílio do programa computacional ESTAT - Sistema para Análise Estatistica 2.0 (Unesp/FCAV).

\section{RESULTADOSEDISCUSSÕES}

\section{Experimento 1}

No momento da aplicação a área experimental encontrava-secomníveis de percevejos próximos de 2 por pano-de-batida, o qual é adotado em lavouras para a produção de grãos como sendo o nível de controle. EMBRAPA SOJA (2006) recomenda o controle quando for constatado um percevejo por pano-de-batida para a produção de sementes e de dois percevejos para grãos.

Não houve interação entre os fatores ponta de pulverização e assistência de ar no controle do percevejo E. heros (Tabela 1). Portanto, a mistura inseticida tiametoxam associado com lambda-cialotrina apresentou desempenho semelhanteno controle de percevejos para as diferentes tecnologias de aplicação. $\mathrm{Na}$ avaliação realizada antes da aplicação (prévia) não houve diferença entre tratamentos e testemunha, evidenciando que a distribuição da população encontrava-se homogênea na área experimental.

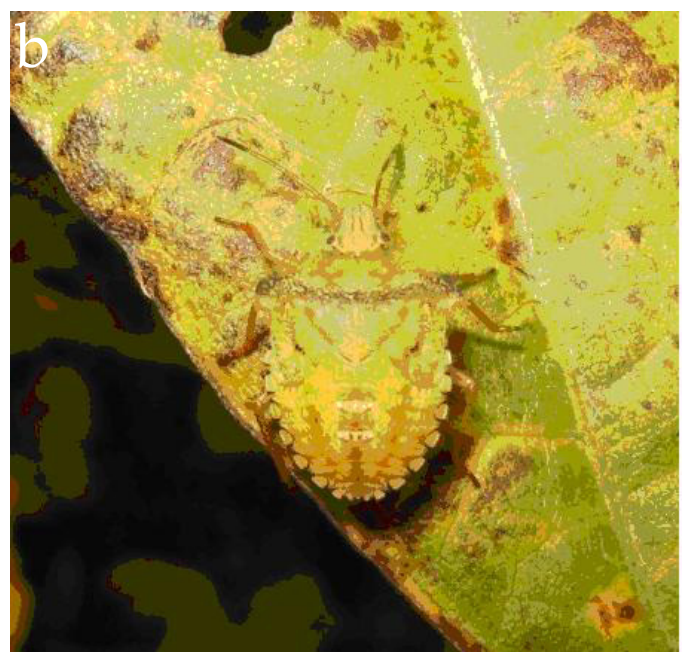

Fig. 1 - Adulto (a) e ninfa de $4^{\circ}$ ínstar (b) do percevejo marrom Euschistus heros. 
A Tabela 1 compara os valores médios do número de percevejos E. heros em função das pontas de pulverização (jato plano e jato cônico vazio) e da assistência de ar junto à barra de pulverização (com e sem assistência de ar), verificando que em todas as avaliações não houve diferença significativa entre elas. Porém, com exceção da avaliação prévia, todos os tratamentos diferiram significativamente do tratamento onde não foi realizado nenhum controle com inseticida.

Tabela 1 - Número médio de Euschistus heros, por pano-de-batida na cultura da soja, em resposta a diferentes tecnologias de aplicação do inseticida tiametoxam associado com lambda-cialotrina e resumo da análise de variância. Botucatu, SP, 2008.

\begin{tabular}{|c|c|c|c|c|c|c|c|}
\hline \multirow[t]{2}{*}{ Tecnologia de aplicação } & \multicolumn{7}{|c|}{ Dias após aplicação } \\
\hline & Prévia & 1 & 3 & 6 & 10 & 14 & Total \\
\hline & \multicolumn{7}{|c|}{ Pontas de pulverização $(\mathrm{P})$} \\
\hline jato plano & $2,1 \mathrm{a}$ & $1,18 \mathrm{~b}$ & $1,10 \mathrm{~b}$ & $1,24 b$ & $1,59 b$ & $1,39 b$ & $3,36 \mathrm{~b}$ \\
\hline \multirow[t]{2}{*}{ jato cônico } & $1,86 a$ & $1,31 b$ & $1,34 b$ & $1,16 b$ & $1,16 b$ & $1,27 b$ & $3,10 \mathrm{~b}$ \\
\hline & \multicolumn{7}{|c|}{ Assistência de ar (A) } \\
\hline sem ar & $1,97 \mathrm{a}$ & $1,23 b$ & $1,31 \mathrm{~b}$ & $1,09 \mathrm{~b}$ & $1,61 \mathrm{~b}$ & $1,38 b$ & $3,32 b$ \\
\hline com ar & $2,0 \mathrm{a}$ & $1,27 \mathrm{~b}$ & $1,13 b$ & $1,30 \mathrm{~b}$ & $1,14 b$ & $1,27 b$ & $3,13 b$ \\
\hline Testemunha $(\mathrm{T})$ & $2,23 a$ & $1,76 a$ & $2,78 \mathrm{a}$ & $2,62 a$ & $3,34 a$ & $3,27 a$ & $6,58 \mathrm{a}$ \\
\hline Valor de F (P) & $0,87^{\mathrm{ns}}$ & $0,46^{\mathrm{ns}}$ & $0,90^{\mathrm{ns}}$ & $0,10^{\mathrm{ns}}$ & $1,40^{\mathrm{ns}}$ & $0,18^{\mathrm{ns}}$ & $0,34^{\mathrm{ns}}$ \\
\hline Valor de F (A) & $0,01^{\mathrm{ns}}$ & $0,04^{\mathrm{ns}}$ & $0,5^{\mathrm{ns}}$ & $0,6^{\mathrm{ns}}$ & $1,68^{\mathrm{ns}}$ & $0,13^{\mathrm{ns}}$ & $0,21^{\mathrm{ns}}$ \\
\hline Valor de $\mathrm{F}(\mathrm{P} \times \mathrm{A})$ & $0,02^{\text {ns }}$ & $0,04^{\mathrm{ns}}$ & $0,5^{\mathrm{ns}}$ & $2,6^{\mathrm{ns}}$ & $0,00^{\mathrm{ns}}$ & $1,74^{\mathrm{ns}}$ & $1,10^{\mathrm{ns}}$ \\
\hline Valor de $\mathrm{F}$ ( $\mathrm{T} \times$ fatores) & $0,65^{\mathrm{ns}}$ & $6,2^{*}$ & $30,6^{* *}$ & $22,5^{* *}$ & $23,4^{* *}$ & $36,9 * *$ & $46,2^{* *}$ \\
\hline C.V.(\%) & 26,8 & 27,5 & 32,8 & 36,2 & 41,2 & 33,5 & 22,61 \\
\hline DMS & 0,59 & 0,40 & 0,55 & 0,59 & 0,79 & 0,57 & 0,96 \\
\hline
\end{tabular}

*significativo a $5 \%$;

**significativo a $1 \%$;

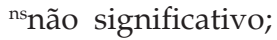

DMS: Diferença Mínima Significativa.

\section{Eficiência de controle (\%)}

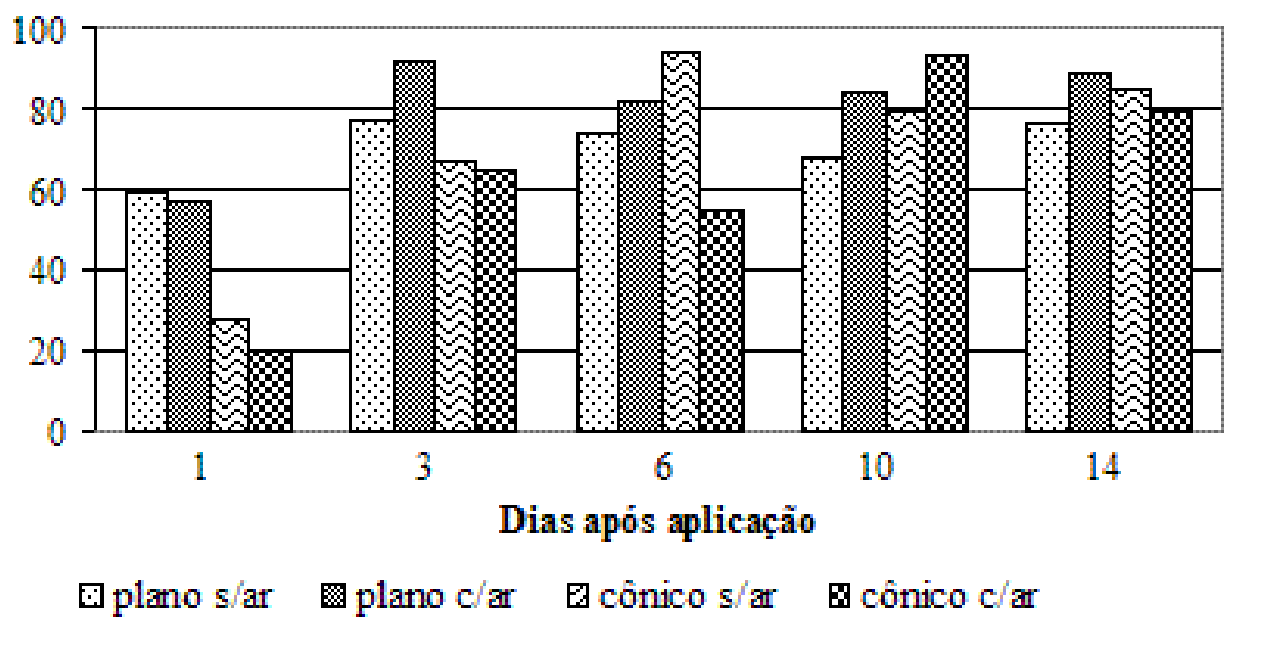

Fig. 2 - Eficiência do inseticida tiametoxam associado com lambda-cialotrina no controle do percevejo E. heros, quando aplicado com pontas de jato plano e cônico vazio, com e sem assistência de ar. Botucatu, SP, 2008. (s/ar = sem assistência de $\operatorname{ar} ; \mathrm{c} / \mathrm{ar}=$ com assistência de ar). 
Pela representação gráfica da Figura 2, utilizando o inseticida tiametoxam associado com lambdacialotrina, nota-se que na avaliação realizada 1 DAA as pontas de pulverização de jato plano apresentaram melhor eficiência decontroleem comparaçãoàs pontas de jato cônico, porém com baixas porcentagens de controle dos insetos. Tal fato pode ser explicado pelo poucotempodeexposiçãoentreinseticida einseto. Aos 3DAA, houveumaumentona porcentagem decontrole do percevejo, destacando-se o tratamento com a ponta de jato plano provida de assistência de ar com eficiência decontrolesuperior a $90 \%$. Com exceção da primeira avaliação(1DAA), o tratamento com a ponta dejato plano na presença da assistência de ar junto à barra de pulverização foi mais eficiente em comparação ao tratamentocom a mesma ponta, porém sem assistência de ar. No geral, todos os tratamentos tiveram comportamentos semelhantes e um controle satisfatório do percevejoem estudo,comeficiência decontroleentre78 a $91 \%$ aos 14 DAA, conferindo um bom efeito residual doproduto.

FARIAS et al. (2006), estudando a eficácia de controle do inseticida tiametoxam associado com lambdacialotrina na dosagem de 25,38 + 19,08 g.i.a. ha ${ }^{-1}$ sobre opercevejo verdepequeno, Piezodorus guildinii, obtiveram eficiência de controle superior a $90 \%$, aos 14DAA.

O número médio do complexo de percevejos nas avaliações prévia, com 1,3,6,10,14DAA edonúmero total acumulado em resposta às pontas de pulverização (jato plano e jato cônico vazio) estão representados na Tabela 2. De modo semelhante aos resultados obtidos para E. heros, não ocorreu interação significativa entre pontas de pulverização e assistência de ar para o complexo de percevejos. Com isso pode considerar que neste experimento a utilização tanto da ponta de jato plano quanto da ponta de jato cônico vazio para o inseticida tiametoxam associado com lambda-cialotrina são estatisticamente iguais. Isso também pode ser observado para o emprego da assistência de ar junto à barra de pulverização, onde as médias não diferiram significativamente entre si. Assim como ocorreu para o percevejo E. heros, analisado isoladamente, todos os tratamentos, com exceção da avaliação prévia, difereriram significativamente da testemunha (Tabela 2).

Ao analisar a eficiência de controle do complexo de percevejos fitófagos na cultura da soja utilizando o inseticida tiametoxam associado com lambdacialotrina em diferentes tecnologias de aplicação(Fig. 3) verifica-se que grande parte dos tratamentos apresentou controle superior a $80 \%$. Observa-se também que os tratamentos apresentaram alta eficiência de controle aos $14 \mathrm{DAA}$, isso pode-se atribuir ao efeito residual da mistura inseticida.

MAZIERO (2006), estudando o efeito de controle do inseticida tiametoxam associado com lambdacialotrina na dosagem de 21,15 + 15,90 g.i.a. ha-1 com diferentes volumes de calda para o precevejo $P$. guildinii, obteve eficiências de controle de 88 e $87 \%$ com volumes de calda de 100 e $150 \mathrm{~L} \mathrm{ha}^{-1}$, respectivamente. Esses resultados assemelham-se aos resultados obtidos neste trabalho, que apresentou porcentagem média de eficiência de controle dos tratamentos com o inseticida tiametoxam associado com lambda-cialotrina para os percevejos fitófagos de 85\% (Fig. 3).

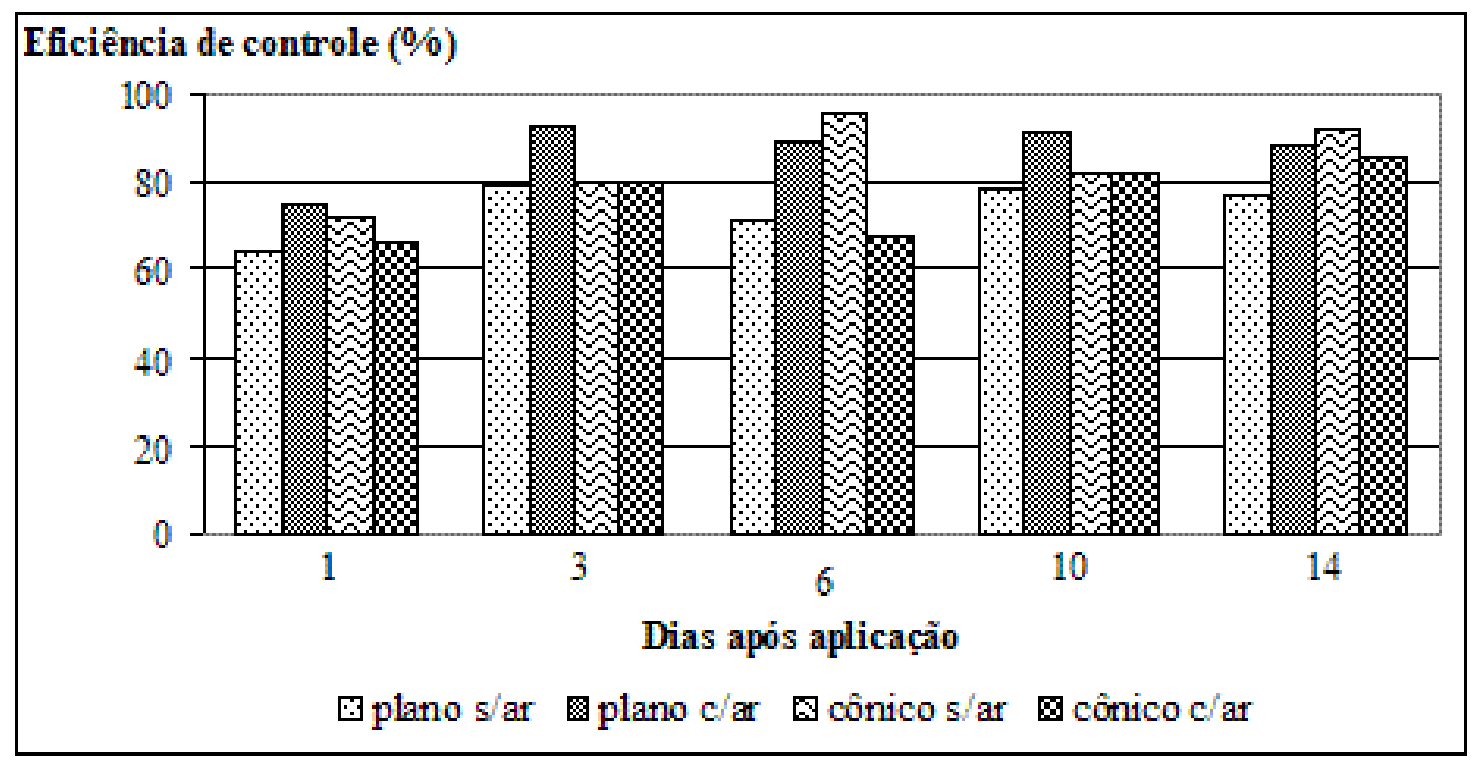

Fig. 3 - Eficiência do inseticida tiametoxam associado com lambda-cialotrina no controle do complexo de percevejos que ocorre na cultura da soja quando aplicado com pontas de jato plano e cônico, com e sem assistência de ar. Botucatu, SP, 2008. (s/a = sem assistência de ar; c/ar = com assistência de ar). 
Tabela 2 - Número médio do complexo de percevejos, por pano-de-batida na cultura da soja, em resposta a diferentes tecnologias de aplicação do inseticida tiametoxam associado com lambda-cialotrina e resumo da análise de variância. Botucatu, SP, 2008.

\begin{tabular}{|c|c|c|c|c|c|c|c|}
\hline \multirow[t]{2}{*}{ Tecnologia de Aplicação } & \multicolumn{7}{|c|}{ Dias após aplicação } \\
\hline & Prévia & 1 & 3 & 6 & 10 & 14 & Total \\
\hline & \multicolumn{7}{|c|}{ Pontas de pulverização $(\mathrm{P})$} \\
\hline jato plano & $2,43 a$ & $1,37 \mathrm{~b}$ & $1,47 \mathrm{~b}$ & $1,18 b$ & $1,92 b$ & $1,54 \mathrm{~b}$ & $3,99 b$ \\
\hline \multirow[t]{2}{*}{ jato cônico } & $2,36 a$ & $1,31 b$ & $1,20 \mathrm{~b}$ & $1,27 \mathrm{~b}$ & $1,52 b$ & $1,39 b$ & $3,57 \mathrm{~b}$ \\
\hline & \multicolumn{7}{|c|}{ Assistência de ar (A) } \\
\hline sem ar & $2,5 a$ & $1,37 \mathrm{~b}$ & $1,26 \mathrm{~b}$ & $1,29 b$ & $1,69 b$ & $1,62 b$ & $3,92 b$ \\
\hline com ar & $2,28 \mathrm{a}$ & $1,31 b$ & $1,41 b$ & $1,16 b$ & $1,75 b$ & $1,31 \mathrm{~b}$ & $3,64 b$ \\
\hline Testemunha $(\mathrm{T})$ & $2,72 a$ & $2,53 a$ & $3,55 a$ & $3,03 a$ & $4,62 \mathrm{a}$ & $4,14 \mathrm{a}$ & $8,47 \mathrm{a}$ \\
\hline Valor de F (P) & $0,10^{\text {ns }}$ & $0,04^{\mathrm{ns}}$ & $0,76^{\mathrm{ns}}$ & $0,11^{\mathrm{ns}}$ & $1,44^{\mathrm{ns}}$ & $0,32^{\mathrm{ns}}$ & $0,69^{\mathrm{ns}}$ \\
\hline Valor de F (A) & $0,82^{\text {ns }}$ & $0,04^{\mathrm{ns}}$ & $0,22^{\text {ns }}$ & $0,20^{\text {ns }}$ & $0,03^{\text {ns }}$ & $1,27^{\text {ns }}$ & $0,29^{\text {ns }}$ \\
\hline Valor de $\mathrm{F}(\mathrm{P} \times \mathrm{A})$ & $0,06^{\mathrm{ns}}$ & 0,22 ns & $0,18^{\mathrm{ns}}$ & $3,80^{\text {ns }}$ & $0,80^{\text {ns }}$ & $3,64^{\mathrm{ns}}$ & $1,84^{\mathrm{ns}}$ \\
\hline Valor de $\mathrm{F}$ ( $\mathrm{T} \times$ fatores) & $1,36^{\mathrm{ns}}$ & $14,2^{* *}$ & $40,2^{* *}$ & $32,6^{* *}$ & $62,5^{* *}$ & $77,3^{* *}$ & $67,6^{* *}$ \\
\hline C.V.(\%) & 20,0 & 35,9 & 35,3 & 35,8 & 28,5 & 27,3 & 21,6 \\
\hline DMS & 0,54 & 0,62 & 0,68 & 0,62 & 0,71 & 0,59 & 1,11 \\
\hline
\end{tabular}

*significativo a $5 \%$;

**significativo a $1 \%$;

${ }^{\text {ns }}$ não significativo;

DMS: Diferença Mínima Significativa.

Tabela 3 - Número médio de Euschistus heros, por pano-de-batida na cultura da soja, em resposta a diferentes tecnologias de aplicação do inseticida endosulfan e resumo da análise de variância. Botucatu, SP, 2008.

\begin{tabular}{|c|c|c|c|c|c|c|c|}
\hline \multirow[t]{2}{*}{ Tecnologia de Aplicação } & \multicolumn{7}{|c|}{ Dias após aplicação } \\
\hline & Prévia & 1 & 3 & 6 & 10 & 14 & Total \\
\hline & \multicolumn{7}{|c|}{ Pontas de pulverização (P) } \\
\hline jato plano & $2,28 \mathrm{a}$ & $1,27 \mathrm{~b}$ & $1,31 b$ & $1,46 b$ & $1,83 b$ & $1,89 \mathrm{~b}$ & $4,04 \mathrm{~b}$ \\
\hline \multirow[t]{2}{*}{ jato cônico } & $1,55 \mathrm{a}$ & $1,41 \mathrm{~b}$ & $1,19 b$ & $1,42 b$ & $1,30 \mathrm{~b}$ & $1,20 \mathrm{c}$ & $3,10 \mathrm{c}$ \\
\hline & \multicolumn{7}{|c|}{ Assistência de ar (A) } \\
\hline sem ar & $1,82 \mathrm{a}$ & $1,36 \mathrm{~b}$ & $1,35 b$ & $1,39 b$ & $1,90 \mathrm{~b}$ & $1,77 \mathrm{~b}$ & $3,81 b$ \\
\hline com ar & $2,02 \mathrm{a}$ & $1,32 b$ & $1,16 b$ & $1,49 b$ & $1,23 \mathrm{c}$ & $1,32 b$ & $3,33 b$ \\
\hline Testemunha(T) & $2,23 a$ & $2,75 a$ & $2,78 \mathrm{a}$ & $2,62 a$ & $3,34 \mathrm{a}$ & $3,28 \mathrm{a}$ & $6,58 \mathrm{a}$ \\
\hline Valor de $F(P)$ & $4,07^{\mathrm{ns}}$ & $0,25^{\mathrm{ns}}$ & $0,35^{\mathrm{ns}}$ & $0,03^{\text {ns }}$ & $2,57^{\mathrm{ns}}$ & $6,13^{*}$ & $5,73^{*}$ \\
\hline Valor de F (A) & $0,33^{\mathrm{ns}}$ & $0,03^{\text {ns }}$ & $0,90^{\mathrm{ns}}$ & $0,16^{\mathrm{ns}}$ & $4,01^{*}$ & $2,55^{\mathrm{ns}}$ & $1,46^{\mathrm{ns}}$ \\
\hline Valor de $F(P \times A)$ & $0,01^{\mathrm{ns}}$ & $1,61^{\mathrm{ns}}$ & $1,63^{\mathrm{ns}}$ & $0,67^{\mathrm{ns}}$ & $0,58^{\mathrm{ns}}$ & $1,03^{\text {ns }}$ & $0,86^{\mathrm{ns}}$ \\
\hline Valor de $\mathrm{F}$ ( $\mathrm{T} \times$ fatores) & $0,61^{\mathrm{ns}}$ & $2,07^{\text {ns }}$ & $44,9 * *$ & $19,7^{* *}$ & $22,4^{* *}$ & $31,1^{* *}$ & $46,6^{* *}$ \\
\hline C.V.(\%) & 36,3 & 37,0 & 26,1 & 28,5 & 34,8 & 29,4 & 18,9 \\
\hline DMS & 0,78 & 0,57 & 0,44 & 0,52 & 0,73 & 0,60 & 0,86 \\
\hline
\end{tabular}

*significativo a $5 \%$;

**significativo a $1 \%$;

${ }^{\text {ns }}$ não significativo;

DMS: Diferença Mínima Significativa.

Esse mesmo autor também relata que elevando o volume de calda de 50 para $150 \mathrm{~L} \mathrm{ha}^{-1}$ foi constatado melhor performance de controle. Esse incremento no controle está associado ao aumento da densidade de gotas, principalmente nas partes mediana e inferior

da cultura. Dessa forma, parte do espectro da névoa produzida com volumes maiores tem maior capacidade de penetração por produzir maior quantidade de gotas finas atingindo os insetos e/ou legumes das partes medianas e inferiores da planta. 
Eficiência de controle (\%)

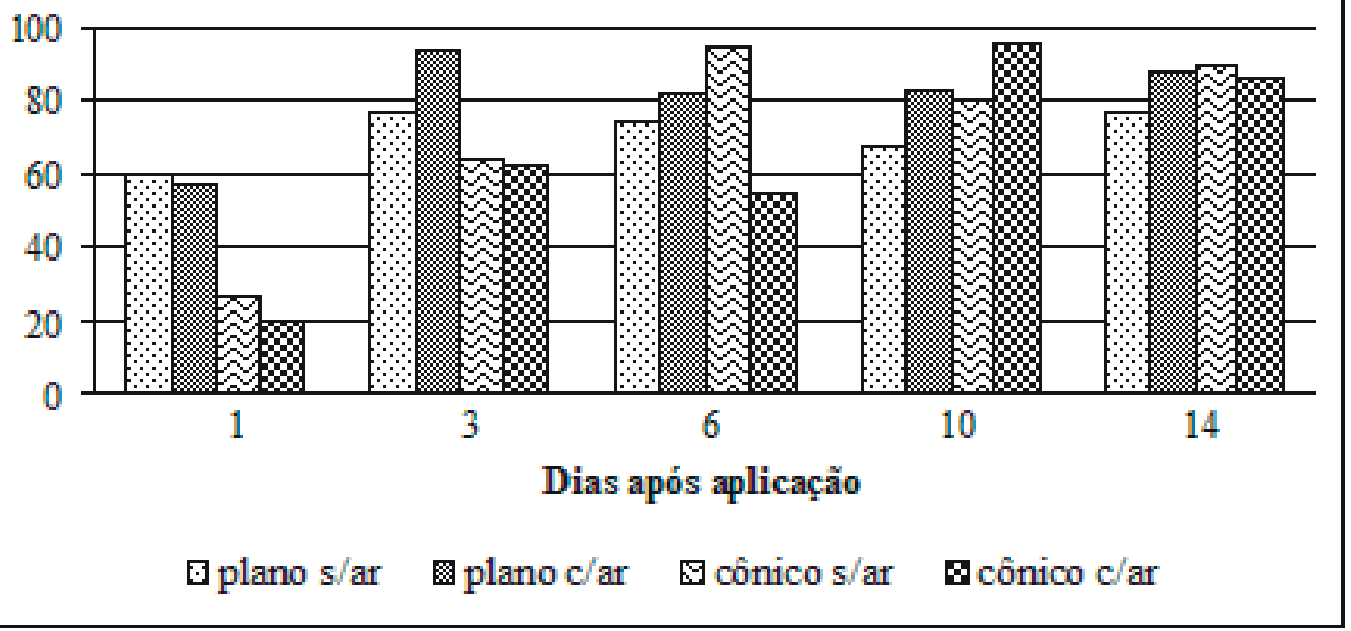

Fig. 4 - Eficiência do inseticida endosulfan no controle do percevejo E. heros, quando aplicado com pontas de jato plano e cônico, com e sem assistência de ar. Botucatu, SP, 2008. (s/ar = sem assistência de ar; c/ar = com assistência de ar).

Tabela 4 - Número médio do complexo de percevejos, por pano-de-batida na cultura da soja, em resposta a diferentes tecnologias de aplicação do inseticida endosulfan e resumo da análise de variância. Botucatu, SP, 2008.

\begin{tabular}{|c|c|c|c|c|c|c|c|}
\hline \multirow[t]{2}{*}{ Tecnologia de Aplicação } & \multicolumn{7}{|c|}{ Dias após aplicação } \\
\hline & Prévia & 1 & 3 & 6 & 10 & 14 & Total \\
\hline & \multicolumn{7}{|c|}{ Pontas de pulverização (P) } \\
\hline jato plano & $3,06 a$ & $1,53 b$ & $1,46 b$ & $1,72 b$ & $2,17 \mathrm{~b}$ & $2,44 \mathrm{~b}$ & $5,14 \mathrm{~b}$ \\
\hline \multirow[t]{2}{*}{ jato cônico } & $2,38 \mathrm{a}$ & $1,55 b$ & $1,54 \mathrm{~b}$ & $1,70 \mathrm{~b}$ & $1,66 b$ & $2,00 \mathrm{~b}$ & $4,31 \mathrm{c}$ \\
\hline & \multicolumn{7}{|c|}{ Assistência de ar (A) } \\
\hline sem ar & $2,52 \mathrm{a}$ & $1,47 \mathrm{~b}$ & $1,43 b$ & $1,76 b$ & $2,13 b$ & $2,21 b$ & $4,68 b$ \\
\hline com ar & $2,92 \mathrm{a}$ & $1,60 \mathrm{~b}$ & $1,56 \mathrm{~b}$ & $1,66 b$ & $1,70 \mathrm{~b}$ & $2,22 b$ & $4,79 b$ \\
\hline Testemunha $(\mathrm{T})$ & 2,72 & 2,53 & 3,55 & 3,03 & 4,62 & 4,14 & $8,47 a$ \\
\hline Valor de F (P) & $4,63^{\mathrm{ns}}$ & $0,01^{\mathrm{ns}}$ & $0,12^{\mathrm{ns}}$ & $0,01^{\mathrm{ns}}$ & $4,22^{\mathrm{ns}}$ & $3,85^{\mathrm{ns}}$ & $5,41^{*}$ \\
\hline Valor de F (A) & $1,6^{\mathrm{ns}}$ & $0,16^{\mathrm{ns}}$ & $0,35^{\mathrm{ns}}$ & $0,18^{\mathrm{ns}}$ & $2,87^{\mathrm{ns}}$ & $0,00^{\mathrm{ns}}$ & $0,07^{\text {ns }}$ \\
\hline Valor de $\mathrm{F}(\mathrm{P} \times \mathrm{A})$ & $0,88^{\mathrm{ns}}$ & $1,68^{\mathrm{ns}}$ & $0,95^{\mathrm{ns}}$ & $3,41^{\mathrm{ns}}$ & $0,88^{\mathrm{ns}}$ & $0,04^{\mathrm{ns}}$ & $0,83^{\mathrm{ns}}$ \\
\hline Valor de $\mathrm{F}$ ( $\mathrm{T} \times$ fatores) & $0,00^{\mathrm{ns}}$ & $7,85^{*}$ & $64,5^{* *}$ & $27,1^{* *}$ & $91,1^{* *}$ & $58,1^{* *}$ & $71,6^{* *}$ \\
\hline C.V.(\%) & 23,4 & 36,5 & 24,0 & 23,0 & 20,6 & 17,3 & 14,4 \\
\hline DMS & 0,69 & 0,63 & 0,50 & 0,49 & 0,55 & 0,49 & 0,81 \\
\hline
\end{tabular}

*significativo a $5 \%$;

**significativo a $1 \%$;

${ }^{\text {ns }}$ ão significativo;

DMS: Diferença Mínima Significativa.

No caso dos experimentos conduzidos neste trabalho, os volumes de calda foram estabelecidos em $200 \mathrm{~L} \mathrm{ha}^{-1}$, apresentando resultados semelhantes quanto a eficiência de controle.

\section{Experimento 2}

Assim como no experimento 1, não houve interação significativa entre os fatores ponta de pulverização e assistência de ar para o percevejo $E$. heros. Comparando-se as pontas de pulverização com o inseticida endosulfan, em cada data de avaliação, verifica-se que aos 14 DAA e o total acumulado obtiveram as menores populações de E. heros nos tratamentos quando utilizada a ponta de jato cônico vazio JA-2. Nas demais avaliações, não houve diferença significativa entre essas duas pontas (Tabela 3). 


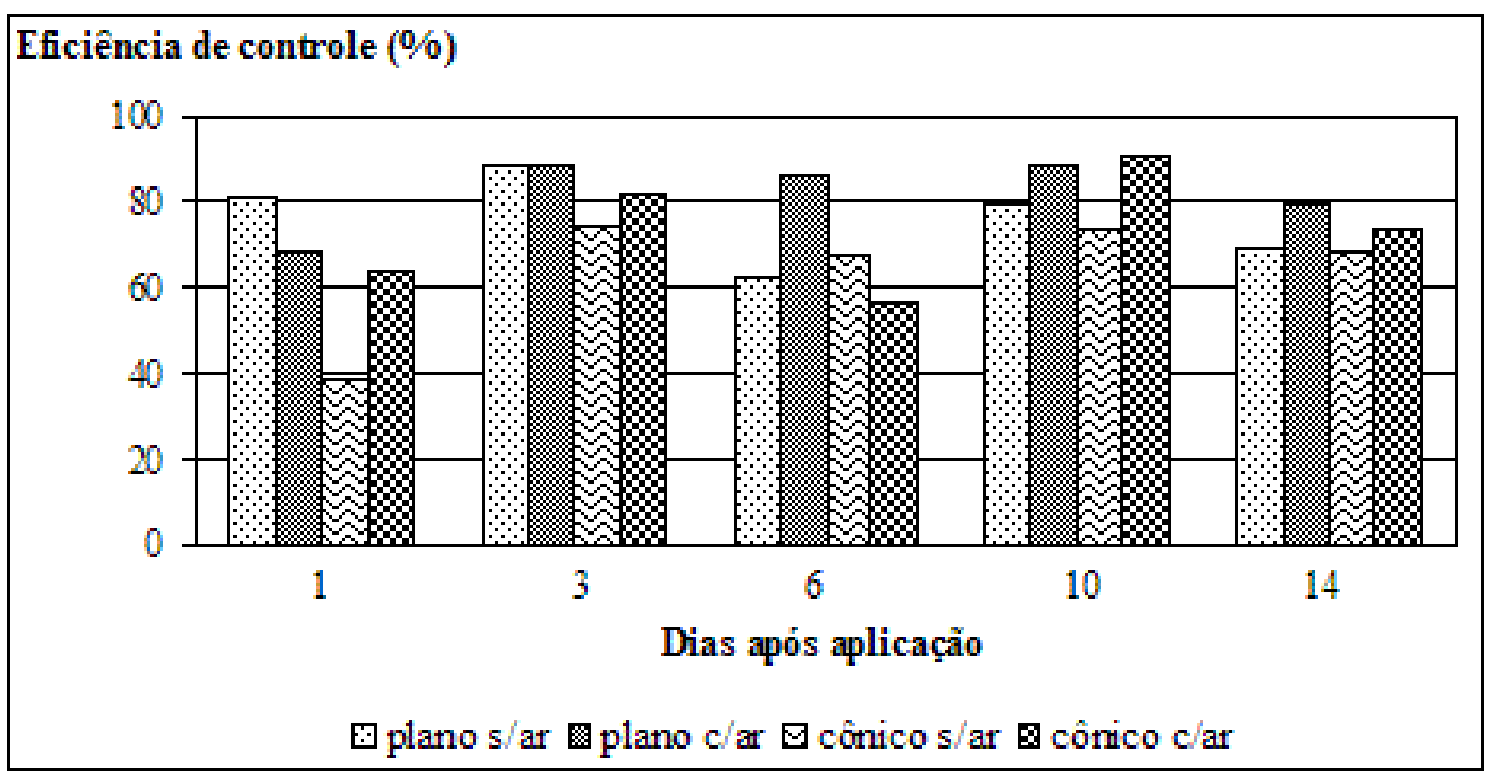

Fig. 5 - Eficiência do inseticida endosulfan no controle do complexo de percevejos que ocorrem na cultura da soja quando aplicado com pontas de jato plano e cônico, com e sem assistência de ar. Botucatu, SP, 2008. (s/ar = sem assistência de ar; $\mathrm{c} / \mathrm{ar}=$ com assistência de ar).

O fato da ponta de jato cônico ter propiciado um melhor controle podeestar associado ao tamanho das gotas produzidas por este tipo de ponta. CUNHA et al. (2004), estudando o tamanho e a densidade das gotas de pontas de jato cônico vazio e plano, relataram que as pontas do tipo cônico vazio apresentam gotas menores em relação àquelas de jato plano, proporcionando maiores densidade de gotas depositadas no alvo, culminando, nesse caso, numa melhor performance do inseticida.

Aos10DAA, os tratamentos comassistência dearna barra de pulverização diferenciaram entre si, onde a assistência de ar contribuiu para um melhor efeito de controle do percevejo $E$. heros pelo inseticida. Nas demais avaliações não foram observadas diferenças estatísticas significativas entre os tratamentos (Tabela 3).

BAUER; RAETANO (2000) concluíram que a assistência de ar junto à barra de pulverização promoveu significativo aumento da deposiçãonas partes média e inferior das plantas de soja.

A Figura 4 apresenta a eficiência de controle do percevejo E. heros com o produto endosulfan com as diferentes tecnologias de aplicação. Assim como no experimento 1 , os tratamentos com a ponta de jato plano com assistência de ar apresentou, embora pequena, melhor eficiência de controle.

No geral, os tratamentos apresentaram eficiência de controle satisfatória para E. heros, acima de $80 \%$ aos 14 DAA, com exceção do tratamento com a ponta de jato plano sem assistência de ar (Fig. 4). FARIAs et al. (2006) obtiveram resultados semelhantes quanto à eficiência de controle de $E$. heros utilizando o insetici- da endosulfan na dosagem de 437,5 g de i.a. ha ${ }^{-1}$, porém os autores relatam que esse inseticida possui baixa seletividade ao complexo de inimigos naturais da soja.

Os valores médios donúmero total docomplexo de percevejos fitófagos nas avaliações prévia, com 1,3,6, 10,14 DAA e o número total acumulado, em resposta as pontas de pulverização (jato plano e jato cônico vazio) e ao uso da assistência de ar junto a barra de pulverização (com e sem assistência de ar) estão descritos na Tabela 4. Assim como no experimento 1, não ocorreu interação significativa entre pontas de pulverização com o fator assistência de ar.

Na avaliação realizada antes da aplicação (prévia) não houve diferença entre tratamentos, dessa forma a população do inseto encontrava-se distribuída de maneira homogênea na área experimental. Foi observado diferença entre os tipos de pontas na avaliação do número total acumulado do complexo de percevejos, sendo quenovamenteos tratamentos com ponta de jato cônico vazio apresentou as menores médias de percevejos fitófagos. Já para o fator assistência de ar não foram observadas diferenças significativas entre a pulverização provida de assistência de ar com a pulverização convencional (Tabela 4).

Em relação à eficiência de controle referente ao complexo de percevejos, observa-se que somente aos 3 DAA obteve-se eficiência satisfatória de controle, com porcentagem de controle se não superior, próxima aos $80 \%$ (Fig. 5). Comparando os experimentos 1 e2 nota-se, ao aplicar a mistura comercial tiametoxam associado com lambda-cialotrina, maior eficiência de 
controle em relação ao inseticida endosulfan. Trabalhos de FARIAs et al. (2006) e MAZIERO (2006) relataram que o inseticida tiametoxam associado com lambdaciatronina apresenta melhores eficiências de controle do percevejo quando comparado ao inseticida endosulfan.

As maiores porcentagens de eficiência no controle dos percevejos com tiametoxam associado com lambda-cialotrina podem estar associadas à redistribuição do tiametoxam na planta, por se tratar de um produto sistêmico, e a menor influência da tecnologia de aplicação. Já o desempenho do endosulfan, um produto com ação de contato e ingestão, é dependente da tecnologia de aplicação. Portanto, pontas de jato cônico vazio que produzem gotas demenorDMV (diâmetromedianovolumétrico), combinadas à assistência de ar junto à barra de pulverização, provavelmente melhoraram a distribuição do produto no dossel da cultura favorecendo o controle de percevejos.

\section{CONCLUSÃO}

Pelos resultados obtidos, conclui-se que não houve interferência do tipo de ponta quando associadas à assistência de ar junto à barra de pulverização no controle de percevejos com a mistura inseticida tiametoxam associado com lambda-cialotrina.

A ponta de jato cônico em presença da assistência de ar junto à barra de pulverização, na velocidade máxima gerada pelo ventilador, tende a melhorar a eficiência de controle de percevejos fitófagos quando utilizado o inseticida endosulfan.

\section{AGRADECIMENTOS}

Ao Conselho Nacional de Desenvolvimento Científico e Tecnológico $(\mathrm{CNPq})$ pelo financiamento e concessão de bolsa ao primeiro autor.

\section{REFERÊNCIAS}

ANTUNIASSI, U.R. Tecnologia de aplicação de defensivos. Rondonópolis: Fundação de Apoio a Pesquisa Agropecuária de Mato Grosso - Fundação MT, 2004. p.165-177. (Boletim Técnico de Soja, n.8).

BAUER, F.C.; ALMEIDA, E.; MARQUES, D.C.; ROSSI, T.; PEREIRA, F.A.R. Deposição de pontas de pulverização AXI 11002 e JA-2 em diferentes condições operacionais. Ciência Rural, v.38, n.6, p.1610-1614, 2008.

BAUER, F.C.; RAETANO, C.G. Assistência de ar na deposição e perdas de produtos fitossanitários em pulverizações na cultura da soja. Scientia Agricola, v.57, n.2, p.271-276, 2000.

CORRÊA-FERREIRA, B.S. Utilização do parasitóide de ovos de Trissolcus basalis (Wollaston) no controle de percevejos da soja. Londrina: Embrapa-CNPSo, 1993. 30p. (Circular técnica, 11).

CUNHA, J.P.A.R.; TEIXEIRA, M.M.; VIEIRA, R.F.; FERNANDES, H.C.; COURY, J.R. Espectro de gotas de bicos de pulverização hidráulicos de jato plano e de jato cônico vazio. Pesquisa Agropecuária Brasileira, v.39, n.10, p.977-985, 2004.

EMBRAPA SOJA. (Brasil). Tecnologias de produção de soja: Região Central do Brasil, 2005. Londrina: Embrapa Soja, 2006. 220p.

FARIAS, J.R.; FRANÇA, J.A.S.; SULZBACH, F.; BIGOLIN, M.; FIORIN, R.A.; MAZIERO, H.; GUEDES, J.V.C. Eficiência de tiametoxam + lambda-cialotrina no controle do percevejo-verde-pequeno, Piezodorus guildinii, (Westwood, 1837) (Hemiptera: pentatomidae) e seletividade para predadores na cultura da soja. Revista da FZVA, v.13, n.2, p.10-19, 2006.

FEHR, W.R.; CAVINESS, C.E.; BURMOOD, D.T.; PENNINGTON, J.S. Stage of development description for soybeans [Glycine max (L.) Merrill]. Crop Science, v.11, n.6, p.929-931, 1971.

GAZZONI, D.L. Efeito de populações de percevejos na produtividade, qualidade da semente e características agronômicas da soja. Pesquisa Agropecuária Brasileira, v.33, n.8, p.1229-1237, 1998.

GODOY, K.B.; ÁVILA, C.J. Parasitismo natural em ovos de dois percevejos da soja, na região de Dourados, MS. Revista de Agricultura, v.75, p.271-279, 2000.

GODOY, K.B.; GALLI, J.C.; ÁVILA, C.J. Parasitismo em ovos de percevejo da soja Euschistus heros (Fabricius) e Piezodorus guildinii (Westwood) (Hemiptera: Pentatomidae) em São Gabriel do Oeste, MS. Ciência Rural, v.35, n.2, p.455-458, 2005.

HENDERSON, C.F.; TILTON, E.W. Tests with acaricides against the brown wheat mite. Journal of Economic Entomology, v.48, n.1, p.157-161, 1955.

MAZIERO, H. Estudo de tecnologia de aplicação e inseticida para o controle de percevejos fitófagos na cultura da soja. 2006. 34f. Dissertação (Mestrado) Universidade Estadual de Santa Maria, Santa Maria, 2006.

RAETANO, C.G.; BAUER, F.C. Efeito da velocidade do ar em barra de pulverização na deposição de produtos fitossanitários em feijoeiro. Bragantia, v.62, n.2, p.329334, 2003. 
RAETANO, C. G.; MERLIN, A. Avanços tecnológicos no controle da ferrugem da soja. In: ZAMBOLIM, L. Ferrugem asiática da soja. Viçosa: UFV, 2006. p.115-138.

RAMIRO, Z.A.; BATISTA FILHO, A.; CINTRA, E.R.R. Eficiência do inseticida actara mix $110+220$ CE (thiamethoxam + cipermetrina) no controle de percevejos praga da soja. Arquivos do Instituto Biológico, São Paulo, v.72, n.2, p.235-243, 2005.

Recebido em 20/12/08

Aceito em 26/5/10 